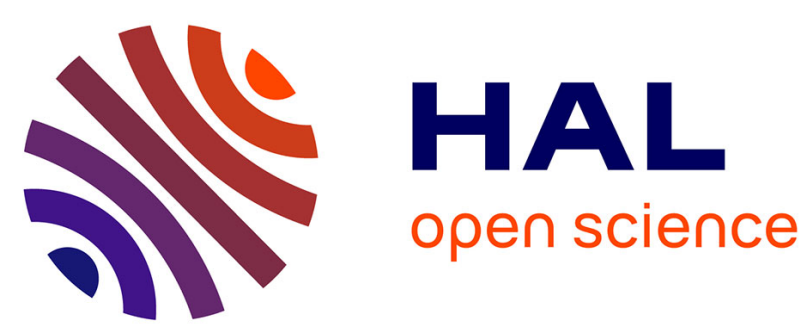

\title{
A combined experimental and theoretical study of the simultaneous occupation of SIa and SIO sites in fully dehydrated K-LSX
}

\author{
Hazar Guesmi, Pascale Massiani, Habiba Nouali, Jean-Louis Paillaud
}

\section{To cite this version:}

Hazar Guesmi, Pascale Massiani, Habiba Nouali, Jean-Louis Paillaud. A combined experimental and theoretical study of the simultaneous occupation of SIa and SI0 sites in fully dehydrated K-LSX. Microporous and Mesoporous Materials, 2012, 159, pp.87-95. 10.1016/j.micromeso.2012.04.011 . hal01054894

\author{
HAL Id: hal-01054894 \\ https://hal.science/hal-01054894
}

Submitted on 11 Aug 2014

HAL is a multi-disciplinary open access archive for the deposit and dissemination of scientific research documents, whether they are published or not. The documents may come from teaching and research institutions in France or abroad, or from public or private research centers.
L'archive ouverte pluridisciplinaire HAL, est destinée au dépôt et à la diffusion de documents scientifiques de niveau recherche, publiés ou non, émanant des établissements d'enseignement et de recherche français ou étrangers, des laboratoires publics ou privés. 


\title{
A combined experimental and theoretical study of the simultaneous occupation of SIa and SI' sites in fully dehydrated K-LSX
}

\author{
Hazar Guesmi ${ }^{1}$, Pascale Massiani ${ }^{1}$, Habiba Nouali ${ }^{2}$ and Jean-Louis Paillaud ${ }^{2 *}$ \\ ${ }^{1}$ CNRS, Laboratoire de Réactivité de Surface, UMR 7197, UPMC, Site d'Ivry - Le Raphaël, 3 \\ rue Gallilée, 94200 Ivry-sur-Seine, France, hazar.guesmi@upmc.fr \\ ${ }^{2}$ Institut de Science des Matériaux de Mulhouse (IS2M), Equipe Matériaux à Porosité \\ Contrôlée (MPC), LRC CNRS 7228 - UHA, ENSCMu, 3 rue Alfred Werner, F-68093 \\ Mulhouse Cedex, France.
}

Corresponding author: jean-louis.paillaud@uha.fr

\begin{abstract}
In the case of fully potassium exchanged X and LSX faujasites, it was reported from a single crystal $\mathrm{X}$-ray study on zeolite $\mathrm{X}$ and preliminary powder $\mathrm{X}$-ray diffraction (PXRD) study on zeolite LSX that $\mathrm{K}^{+}$ions can be found concomitantly in both sites I and I' with partial or full occupancy of site I inside the hexagonal prism depending on the $\mathrm{Si} / \mathrm{Al}$ ratio of the matrix. Such experimental observation of a simultaneous occupancy of adjacent SI and SI' sites in fully exchanged and dehydrated K-LSX was next supported by a theoretical study using the Mott-Littleton approach and a set of formally charged parameters to describe the zeolite. Here, the more appropriate Density Functional Theory (DFT) has been applied to identify the sitting, coordination, environment and properties of the exchanged cations, DFT being indeed recognized as a very successful tool to study the interactions of cations with
\end{abstract}


their environment in zeolites. This approach has been associated to new experimental knowledge gained from argon adsorption measurements and a reinvestigation of the K-LSX structure from Rietveld refinement, to provide an accurate description of not solely the most favorable $\mathrm{K}^{+}$locations inside the hexagonal prisms of fully exchanged K-LSX, but also of the bonding scheme of all exchanged $\mathrm{K}^{+}$ions with respect both to each other and to the zeolitic framework. To understand further the origin of the particular sitting of $\mathrm{K}^{+}$ions in faujasite, calculations have been also performed on Na-LSX, taken as a reference system. Thus, a critical $\mathrm{K}^{+}-\mathrm{K}^{+}$distance was determined from which the charges of potassium cations become equivalent and therefore induces the stability of the system.

Keywords: DFT, dehydrated LSX zeolite, orthorhombic faujasite, potassium exchanged, cationic sites, Rietveld refinement, argon adsorption.

\section{Introduction}

Due to their interest in numerous adsorption and catalytic applications, a large amount of studies has been made since long to identify the location of cations - especially alkali ones in faujasite zeolite (FAU) structures. A wide literature exists on this topic, involving both experimental [1,2,3] and theoretical approaches [4], as has been reviewed recently [5]. From these studies, well-referenced cationic locations have been established, classically referred to as site SI (at the center of the hexagonal prism), site SI' (within the sodalite cages, facing the center of the 6-membered ring (6-MR) windows of the hexagonal prism), sites SII, SIII and SIII' (three different possible positions inside the supercages) and sites SII', SIV, SV, SU (all more rarely occupied than the previous sites) (Figure 1A). In some cases, small displacements from the most widely reported centred positions have been described, especially when not 
perfect symmetrical Al distributions - and therefore different basic strengths of the lattice oxygen atoms - occur within the framework [6,7]. As can be expected, the site occupancy varies depending on both the nature and the content of the cations, the latter being determined by the framework Al content. Besides, the occupancy can strongly change upon addition of adsorbed molecules that can displace the exchanged ions, as is for instance the case with water which by forming bulky hydration spheres around the cations can extract them from the inside of the hexagonal prisms towards less constrained locations, in sodalite cages or in supercages [8].

\section{Insert Figure 1}

Amongst the general consensus and known trends, it is widely admitted that simultaneous cationic occupancy of sites SI and SI' should not occur in faujasite due to cation-cation electrostatic repulsion [9]. Nevertheless, one of us previously concluded in a preliminary Xray diffraction (XRD) report that after full exchange by $\mathrm{K}^{+}$ions and full dehydration of a LSX (Low Silica X), $\mathrm{K}^{+}$ions can be found concomitantly in both sites I and I' (although slightly shifted from their classical central positions) [10].This was also seen in anhydrous similar $\mathrm{X}$ zeolite with $\mathrm{Si} / \mathrm{Al}=1.09$ [11]. LSX is a zeolite with FAU topology characterized by a framework $\mathrm{Si} / \mathrm{Al}$ ratio of 1 , this implies, in accordance with the Lowenstein's Al-O-Al avoidance rule [12], a perfect alternation of $\mathrm{Si}$ and $\mathrm{Al}$ tetrahedra in the lattice. The experimental observation of a simultaneous occupancy of adjacent SI and SI' sites in dehydrated K-LSX was next supported by a theoretical study [13] in which the authors applied the Mott-Littleton approach and a set of formally charged parameters to describe the zeolite. Although this method is known to provide a satisfying average tendency of cation location in zeolites, it relies upon the use of empirical inter-atomic potentials that are not able 
to describe the characteristics of bonds in the system with great accuracy. A more appropriate way to identify the sitting, coordination, environment and properties of the exchanged cations is the Density Functional Theory (DFT) approach that is indeed recognized as a very successful tool to study cation interactions in zeolites $[14,15]$. Our goal herein, is to use such DFT method, associated to experimental knowledge gained from gravimetric (TG) measurements and XRD refinement, to provide an accurate description of not solely the most favorable $\mathrm{K}^{+}$locations inside the hexagonal prisms of fully exchanged K-LSX, but also of the bonding scheme of the exchanged $\mathrm{K}^{+}$ions with regard both to each other and to the zeolitic framework. To understand further the origin of the particular sitting of $\mathrm{K}^{+}$ions in faujasite, calculations were also performed on Na-LSX, taken as a reference system.

The paper is organized as follows. After a description of the experimental and theoretical methodologies, the results are presented in section 3 . The crystallographic data evidencing the simultaneous $\mathrm{K}^{+}$occupancy of sites SI and SI' are first detailed and the Rietveld structural interpretation is optimized by taking into account the few argon molecules that are found to be adsorbed into the zeolite previous to the XRD experiment, due to transfer in a glove-box. Such adsorption is also confirmed by argon adsorption measurements. Next, the computed DFT energetic and geometric results for the most probable K-LSX and Na-LSX configurations are presented and discussed in view of available bibliography. Finally, the particular $\mathrm{K}^{+}$distribution in K-LSX and its specificity as compared to the Na-LSX system is analyzed based on the combined experimental and theoretical structural results and on cation charges derived from Natural Bond Orbital (NBO) analysis. 


\section{Methodology}

\subsection{Materials and experiments}

The fully potassium exchanged LSX sample, namely K-LSX, was prepared as detailed earlier [10]. Its chemical formula $\left|\mathrm{K}_{95.6} \mathrm{Na}_{0.4}\right|\left[\mathrm{Si}_{96} \mathrm{Al}_{96} \mathrm{O}_{384}\right]$ obtained by atomic absorption after dissolution in HF (Varian AFS240 apparatus) confirmed the quasi full exchange of $\mathrm{Na}^{+}$ by $\mathrm{K}^{+}$cations in this sample.

Before X-ray data collection, the sample was dehydrated and sealed under vacuum $\left(2 \times 10^{-4}\right.$ Torr) at $723 \mathrm{~K}$ for 24 hours in a glass tube, which was transferred in a glove box filled with a dried argon atmosphere. Inside the glove-box kept at a temperature of $295 \mathrm{~K}$, the tube was opened, the zeolite powder was transferred into a glass capillary for powder XRD analysis and the capillary was sealed with fast grip glue. The powder XRD data of the sample was collected between 4 and $80^{\circ}(2 \theta)\left(\right.$ step $\left.0.01^{\circ}\right)$ on a STOE STADI-P diffractometer in DebyeScherrer geometry, equipped with a linear position-sensitive detector $\left(6^{\circ}\right.$ in $\left.2 \theta\right)$ and employing Ge monochromated CuKal radiation ( $\lambda=1.5406 \AA$ ). The Rietveld refinement was performed with the GSAS package [16]. All atoms were refined isotropically and soft restraints were placed on framework bond lengths and angles $(\mathrm{Si}-\mathrm{O}=1.62(2) \AA, \mathrm{Al}-\mathrm{O}=$ $1.73(2) \AA$ and $\left.\mathrm{O}-\mathrm{T}-\mathrm{O}=109.5(50)^{\circ}\right)$.

Argon adsorption measurements were carried out at $295 \mathrm{~K}$ using a Micromeritics ASAP 2010 volumetric adsorption analyzer. Before adsorption, the sample was degassed three times for 6 hours at $573 \mathrm{~K}$ under vacuum $\left(2 \times 10^{-3}\right.$ Torr $)$ on the analysis port of the instrument, pure gaseous helium being re-adsorbed between each cycle in order to ensure cleaning of the pores and of the surfaces. Then, the argon adsorption isotherm (Figure 3) of the dehydrated K-LSX sample determined at $295 \mathrm{~K}$ was plotted for relative pressures $\mathrm{P} / \mathrm{P}_{0}$ between 0.1 and 1 with $\mathrm{P}_{0}$ $\approx 740$ Torr. 


\subsection{Computational details}

The Na-LSX and K-LSX systems were modelled as follows. First, the $\mathrm{Na}_{96} \mathrm{Si}_{96} \mathrm{Al}_{96} \mathrm{O}_{384}$ chemical composition of the Na-LSX faujasite unit cell was considered. A perfect alternation of the $\mathrm{SiO}_{4}$ and $\mathrm{AlO}_{4}$ tetrahedra in the FAU lattice was applied and the distribution of the extra-framework cations among the different well-referenced cationic sites was modelled by selecting the distribution defined by Viatle et al. [17], that corresponds to $32 \mathrm{Na}^{+}$ions located in site SI' (in the sodalite cage), $32 \mathrm{Na}^{+}$ions in site SII (in the supercage, facing the 6-MR window of a sodalite cage), and $32 \mathrm{Na}^{+}$ions in site SIII (in the plane of the 12-MR windows, in the supercage). The second step consisted of cutting out from the above Na-LSX zeolite lattice, a cluster of 120 atoms, $\mathrm{Na}_{12} \mathrm{Al}_{12} \mathrm{Si}_{12} \mathrm{O}_{60} \mathrm{H}_{24}$, representing the hexagonal prism and a part of its environment [6]. In this cluster, all dangling bonds were saturated with $\mathrm{H}$ atoms, resulting in $-\mathrm{OH}$ terminations set to $1.0 \AA$ and oriented towards the direction of the next tetrahedral site. The $\mathrm{K}_{12} \mathrm{Al}_{12} \mathrm{Si}_{12} \mathrm{O}_{60} \mathrm{H}_{24}$ model cluster of $\mathrm{K}$-LSX was next constructed by replacing the $\mathrm{Na}^{+}$ions by $\mathrm{K}^{+}$cations. The last step consisted of optimizing the geometric structures of both the $\mathrm{Na}_{12} \mathrm{Al}_{12} \mathrm{Si}_{12} \mathrm{O}_{60} \mathrm{H}_{24}$ and $\mathrm{K}_{12} \mathrm{Al}_{12} \mathrm{Si}_{12} \mathrm{O}_{60} \mathrm{H}_{24}$ clusters, all atoms being allowed to relax except the hydrogen terminations that were kept frozen all along subsequent calculations.

Density Functional Theory (DFT) calculations were performed using the Gaussian 03 package [18] and the Becke3-Lee-Yang-Parr (B3LYP) hybrid functional [19-20] was applied for geometry optimizations. For all atoms, basis sets at the $6-311 \mathrm{G}(\mathrm{d}, \mathrm{p})$ level were used and the optimized geometries were obtained with an energy convergence criterion of at least $10^{-7}$ Ha and a maximum gradient norm of the Cartesian gradient of $10^{-4} \mathrm{Ha} \cdot \mathrm{Bohr}^{-1}$. No corrections were made with respect to the basis set superposition error (BSSE) [21]. 


\section{Results and discussion}

\subsection{Experimental identification of $K^{+}$distribution in dehydrated $K$-LSX}

zeolite

The sitting of the potassium cations exchanged in K-LSX zeolite previously dehydrated by evacuation $\left(2 \times 10^{-4}\right.$ Torr $)$ at $723 \mathrm{~K}$ for 24 hours was experimentally identified by X-ray diffraction combined to Rietveld analysis of the obtained data. Figure 2 shows the Rietveld plot.

Insert Figure 2

In the earlier preliminary Rietveld refinement in which the actual $\left|\mathrm{K}_{95.6} \mathrm{Na}_{0.4}\right|\left[\mathrm{Si}_{96} \mathrm{Al}_{96} \mathrm{O}_{384}\right]$ formula of the dehydrated K-LSX sample was considered, an orthorhombic space group $(F d d d)$ in place of the more usual cubic ones for faujasites was identified [10]. Also, the first most intense diffraction peak at $2 \theta$ around $6^{\circ}$, assigned to Miller indices $(1,1,1)$, could not be taken into account due to its bad fit [10] which was explained at this stage by a too strong peak asymmetry at low angle. Nevertheless, it has to be recalled that previous to XRD recording, the thermally evacuated sample had to be put in a glove box filled with dry argon to be transferred into the capillary before $\mathrm{XRD}$ data collection, thus allowing a direct contact of the zeolite with the argon atmosphere. Therefore, argon adsorption inside the faujasite supercage was suspected and such adsorption was recently confirmed by conducting a volumetric Ar adsorption isotherm study. The latter shows a regular increase of the volume of adsorbed Ar as a function of the relative pressure (Figure 3) until reaching a maximum volume $\mathrm{V}_{\max }=3.8 \mathrm{~cm}^{3} \cdot \mathrm{g}^{-1}\left(0.17 \mathrm{mmol} . \mathrm{g}^{-1}\right.$ or about 2.6 molecules per unit cell of K-LSX) for 
$\mathrm{P} / \mathrm{P}_{0}$ pressure ratios ranging from 0.82 to $0.97\left(\mathrm{P}_{0} \approx \mathrm{P}_{\mathrm{atm}}\right)$. This volume represents a mass uptake of about 0.7 weight $\%$ of argon trapped in the dehydrated K-LSX sample.

\section{Insert Figure 3}

Taking this argon adsorption into consideration, a new Rietveld analysis of the full XRD pattern was made, starting from the final previous model [10]. Table 1 details the crystallographic and Rietveld refinement parameters, while Table 2 reports all refined atomic coordinates and site occupancy factors. Lists of selected bond distances and bond angles are given in Table S1, S2 and S3 of Supporting Information together with a CIF file.

Insert Tables 1, 2

As can be seen on Figure 2 (see especially "difference" plot, in blue), the refinement led to an excellent agreement between the experimental and simulated patterns. The $\left|\mathrm{Ar}_{3.15} \mathrm{~K}_{93.68}\right|\left[\mathrm{Si}_{96} \mathrm{Al}_{96} \mathrm{O}_{384}\right]$ unit cell content for the final refinement is moreover found close to the $\left|\mathrm{K}_{95.6} \mathrm{Na}_{0.4}\right|\left[\mathrm{Si}_{96} \mathrm{Al}_{96} \mathrm{O}_{384}\right]$ formula of chemical analysis and it involves a calculated $\mathrm{Ar}$ content (about 0.83 weight $\%$ ) of the order of the one measured by volumetry $(\approx 0.7 \%$ ), although slightly higher, probably due to the argon pressure of 760 Torr in the glove box instead of 740 Torr (reference $\mathrm{P}_{0}$ value) during the adsorption measurement. The average $\mathrm{Si}-\mathrm{O}$ and $\mathrm{Al}-\mathrm{O}$ distances are 1.61(1) and 1.73(1) $\AA$ (Table S1), the mean O-Si,Al-O and $\mathrm{Si}-\mathrm{O}-\mathrm{Al}$ bond angles values are 109.45 and $145.49^{\circ}$ (Tables S2-3), and the standard deviation are 2.5 and $8.6^{\circ}$, respectively.

Compared to the preliminary study [10], only very small changes were noted in terms of positions and occupancy of extra-framework cationic sites (Figure 1B). The sole difference 
was the presence of adsorbed argon atoms (3.15 atoms per unit cell) positioned inside the supercages near site SV [22], i.e. close to the center of the aperture between two supercages defined by $12 \mathrm{MRs}$. This is seen on Figure 4 (plotted with all refined atomic positions [23]) where the various locations as well as the interactions of extra-framework $\mathrm{K}^{+}$and Ar between each other and with the lattice are better visualized. In such SV site, Ar is at distances of 4.37(8) and 5.16(8) $\AA$ of $\mathrm{K}^{+}$ions in sites SIII1 and SIII2, respectively (Table S1). This refined position was established to perfectly fit the positive residual electronic density on the Fourier transform map. It is worth to note that the possible presence of water in place of argon was also envisaged for the sake of completion (full dehydration is indeed know difficult in hydrophilic Al-rich zeolites such as LSX) but the molecules would then be at distances of the cationic sites lower than $3 \AA$ (water tends to approach positively charged ions, thus forming hydration spheres around them), in contrast with the measured distances. Besides, the $\mathrm{K}^{+}$ions occupy five distinct crystallographic sites, namely SI' and SII (as cited above), SIII1 and SIII2 (both of SIII type but with slightly different characteristics) and the denoted SIa site that corresponds to a shifted position from the center of the hexagonal prism as found for site SI in a normal cubic faujasite. Thus, a very peculiar cationic distribution is found in dehydrated KLSX since sites SIa and SI' are simultaneous occupied, which is usually considered hardly feasible in faujasites (see below). From Table SI, very short $\mathrm{K}^{+}-\mathrm{K}^{+}$distances of around 3.52(1) $\AA$ are identified for such sites.

Insert Figure 4 


\subsection{DFT optimized cation locations inside the extended hexagonal prism}

Previous theoretical confirmation of the simultaneous occupancy of SI and SI' sites in dehydrated K-LSX has been given, based on calculations involving empirical inter-atomic potentials that can provide average tendencies on cationic locations [13]. Nevertheless, deeper understanding of the origin of such specific $\mathrm{K}^{+}$configuration requires that more information on parameters such as the local charges or the characteristics of the cation-cation and cationframework interactions be reached. To this aim, geometrical DFT optimization of the K-LSX system was made. For the sake of calculation cost saving, the calculations were restricted to the LSX extended hexagonal prism (built as explained in section 2.2, see scheme in Figure 5A), which allows the modeling of both SI and SI' site occupancy. Calculations were also performed considering full exchange with $\mathrm{Na}^{+}$ions in order to allow comparison with the Na-LSX system, taken as reference.

\section{Insert Figure 5}

It can be recalled that both K-LSX and Na-LSX clusters involve twelve exchangeable cations, amongst which six occupy SII sites. This implies full occupancy of the available SII sites (six per cluster) in agreement with literature that considers these sites as the energetically most favorable ones for alkali ions [24-25]. The location of the other six cations was optimized considering four different starting configurations. In configuration 1, all six cations are positioned at SIII sites at the exterior of the hexagonal prism (no cation inside the hexagonal prism). In configuration 2, one cation is placed inside the prism at site SI (the five remaining cations occupy SIII sites). In configuration 3, two cations are positioned in the two available SI' sites, at the 6-MR entrance windows of the prism (the four remaining cations occupy SIII sites). Finally, in configuration 4, two cations are placed simultaneously in SI and 
SI' sites (the four remaining cations occupy SIII sites). The minimum energy values of the equilibrium geometries (EG) deduced from DFT optimizations of the four configurations for both $\mathrm{Na}_{12} \mathrm{Al}_{12} \mathrm{Si}_{12} \mathrm{O}_{60} \mathrm{H}_{24}$ and $\mathrm{K}_{12} \mathrm{Al}_{12} \mathrm{Si}_{12} \mathrm{O}_{60} \mathrm{H}_{24}$ clusters are reported in Table 3. Let us add that additional DFT optimization tests show that configurations including not fully occupied SII sites have the lower DFT energy values and thus such configurations were not considered.

\section{Insert Table 3}

The first straightforward information provided by energy values concerns the Na-exchanged LSX system for which only three configurations appear feasible. Indeed, no equilibrium geometry is found for the last configuration with simultaneous SI and SI' sites occupancies. This is in line with bibliography that widely considers this adjacent placements highly improbable for $\mathrm{Na}^{+}$ions due to electrostatic repulsion (sites too close to each other to easily accommodate two positively charged ions [26]). Then, the most energetically stable Na-LSX structure is found when two $\mathrm{Na}^{+}$cations occupy both SI' sites (configuration 3), in line with literature [27], whereas configurations 1 and 2 appear less favorable $(\Delta \mathrm{E}=+236$ and +105 $\mathrm{kJ} \mathrm{mol}^{-1}$, respectively). Turning to the K-LSX cluster, configuration 3 appears again energetically favored, as for Na-LSX, but this configuration is energetically equivalent to configuration 4, suggesting a competition and therefore coexistence of the two configurations in dehydrated K-LSX. Consequently, simultaneous $\mathrm{K}^{+}$sitting in both SI and SI' sites is definitively expected in K-LSX, in strong contrast with the classical situation encountered in alkali-exchanged faujasites. Next, compared to these two energetically preferred configurations, both configurations 1 (with no $\mathrm{K}^{+}$inside the hexagonal prism) and 2 (one $\mathrm{K}^{+}$ in SI) in K-LSX are predicted less favorable, although to a lesser extent for the latter $(\Delta \mathrm{E}=$ 
+210 and $+50 \mathrm{~kJ} \cdot \mathrm{mol}^{-1}$, respectively). Upper and side views of the optimized DFT clusters for K-LSX configurations 2, 3 and 4 are shown in Figure 5B, C and D, in that order.

\subsection{Cation coordination and neighbouring in the hexagonal prism}

In addition to configuration 4 in which SI (SIa) and SI' sites are simultaneously occupied, the DFT results predict two other energetically stable types of $\mathrm{K}^{+}$occupancy inside the hexagonal prism of K-LSX (the highly endothermic configuration 1 is excluded).

In configuration 2 (Figure 5B), the potassium cation is located at the center of the prism, with octahedral coordination to six oxygen atoms positioned three by three in the upper and in the bottom 6-MRs of the hexagonal prism, respectively. The calculated average $\mathrm{dK}(\mathrm{SI})-\mathrm{O}$ bond length is $2.75 \AA$, which is slightly longer than the sum $(2.65 \AA)$ of the ionic radii of $\mathrm{K}^{+}$ $(1.33 \AA)$ and $\mathrm{O}^{2-}(1.32 \AA)$ [28]. As indicated in an earlier synchrotron X-ray powder diffraction study on fully K-exchanged and hydrated LSX [29], these cations are 2.782(5) $\AA$ away from the six corresponding framework oxygen atoms in a perfect octahedral coordination sphere, i.e. at distance very close to the above calculated value.

In configuration 3, the two available SI' sites are occupied by two potassium ions. The precise location of each $\mathrm{K}^{+}$ion is shifted from the plane of its corresponding 6-MR by $1.10 \AA$ and the resulting $\mathrm{dK}^{+}\left(\mathrm{SI}^{\prime}\right)-\mathrm{K}^{+}\left(\mathrm{SI}^{\prime}\right)$ bond length equals $5.89 \AA$ (Figure $5 \mathrm{C}$ ). In this highly symmetrical configuration of the prism, each potassium cation interacts with three oxygen atoms of the close 6-MR, the average $\mathrm{dK}\left(\mathrm{SI}^{\prime}\right)-\mathrm{O}$ bond length being $2.64 \AA$, and this forms an image opposite to the other one with respect to the center of the hexagonal prism. Compared to potassium, the computed positions of sodium in Na-LSX starting from configuration 3 strongly differ since the two $\mathrm{Na}^{+}$cations are in the plane of the two 6-MRs, each being coordinated to four framework oxygen atoms with shorter $\mathrm{dNa}^{+}\left(\mathrm{SI}^{\prime}\right)-\mathrm{O}$ average bond length 
$(2.34 \AA)$ than above (more details on Na-LSX can be found in reference [6]). Moreover, the predicted $\mathrm{dNa}^{+}\left(\mathrm{SI}^{\prime}\right)-\mathrm{Na}^{+}(\mathrm{SI}$ ') bond length is $4.08 \AA$, significantly shorter than for the exchanged potassium ions.

Finally, in the highly stable configuration 4 with simultaneous SI and SI' occupancy, one of the two $\mathrm{K}^{+}$occupies the denoted SIa site which is a site shifted along the 3 -fold axis from the center of the hexagonal prism by $0.48 \AA$ towards the bottom part of the hexagonal prism (Figure 5D). At this position, the potassium cation binds six oxygen atoms from the bottom and upper the 6-MRs through three short (2.60 $\AA)$ and three long (2.99 $\AA)$ bonds respectively. The calculated average $\mathrm{dK}(\mathrm{SIa})-\mathrm{O}$ bond length is $2.80 \AA$ The other $\mathrm{K}^{+}$cation is located in SI' site at $1.39 \AA$ above the mean plane of the upper $6-\mathrm{MR}$. The calculated $\mathrm{dK}^{+}(\mathrm{SIa})-\mathrm{K}^{+}$(SI') bond length is $3.59 \AA$. The $\mathrm{K}^{+}$cation forms a pyramidal connection with three oxygen atoms from the upper 6-MR (Figure 5D), with an average dK(SI')-O bond length of $2.71 \AA$. This computed configuration concords with our experimental measurements, the present structural study giving a slightly more distorted geometry. Indeed, the shift of the SI position towards the SIa one is of $0.45 \AA$ along the 3 -fold axis (Figure $6 \mathrm{~A}$ ). The SIa-O short distances range from 2.53(1) to 2.84(1) $\AA$ from the bottom 6-MR and the three shortest distances with the upper 6-MR from 2.98(1) to 3.41(1) $\AA$ (Figure 6B and Table S1). The SI' site is $1.44 \AA$ above the mean upper 6-MR plane (Figure 6A). The site SI' formed a distorted pentagonal pyramid with 5 oxygen atoms of the upper 6-MR, the corresponding distances varying from 2.77(1) and 2.88(2) $\AA$ (Figure $6 \mathrm{~B}$ and Table S1). The sixth oxygen atom of the upper 6-MR (O4) is further away and located at 3.74(2) from this SI' site.

In their single crystal XRD study of fully dehydrated $\mathrm{K}^{+}$-exchanged cubic zeolite $\mathrm{X}$, Zhu and Seff [11] have mentioned the co-existence of three configurations, similar to the herein DFT predicted configurations. These authors have reported that amongst the 16 hexagonal prisms per unit cell, eight have SI and SI' sites simultaneously occupied, six contain one $\mathrm{K}^{+}$ 
ion at site SI, and two have two $\mathrm{K}^{+}$ions at SI' sites, one on each side. The eight potassium ions occupying the site similar to our denoted SIa site were $0.4 \AA$ off the center along a 3-fold axis, 2.468(15) $\AA$ from three oxygen atoms of the bottom 6-MR and 2.913(19) $\AA$ from the remaining three of the upper 6-MR. Later, Seff and co-workers [30] have detected the same potassium positions in $\mathrm{K}-\mathrm{Y}$ faujasite and they have noticed that $\mathrm{K}^{+}$continues to crowd into site I and I'. Such simultaneous occupancy was on the contrary never mentioned for other alkali. Therefore, it seems to be highly specific to potassium exchanged faujasite. In our K-LSX sample, the distances and angles around the framework and extra framework atoms, listed in Tables S1, S2 and S3 as well as the higher distortion found (Figure 6) suggest that only the configuration where potassium simultaneously occupy SIa and SI' sites occurs. This may be due to the $\mathrm{Si} / \mathrm{Al}$ molar ratio of 1 i.e. a strict silicon aluminum alternation and a maximum of potassium cations per unit cell of the K-LSX zeolite compared to K-X and K-Y zeolites, thus favoring a single configuration. In addition, it is clear that the distortion observed in our samples, found also in computed configuration 4 , is forced by the simultaneous occupancy of both sites SIa and SI' with all hexagonal prisms occupied by one potassium cation. This explains, logically, the observable lowering of the symmetry from cubic to orthorhombic as also proved earlier by ${ }^{29} \mathrm{Si}$ solid state MAS NMR [10] with a tripling of the number of silicon T sites.

\section{Insert Figure 6}

Finally, the half occupancy of site I' (see Table 2) involves that each sodalite cages contains two potassium cations which together with the orthorhombic distortion lead to three different possible arrangements of the cations inside the hexagonal prisms and the sodalite cages. In all three cases there are common $\mathrm{K}^{+}(\mathrm{SIa})-\mathrm{K}^{+}(\mathrm{SI}$ ') distance of $3.52(2) \AA$ and three distinct 
$\mathrm{K}^{+}\left(\mathrm{SI}^{\prime}\right)-\mathrm{K}^{+}\left(\mathrm{SI}^{\prime}\right)$ distances of 3.51(2) $\AA$ (Figure 7A), 4.20(2) $\AA$ (Figure 7B) and 4.23(2) $\AA$ (Figure $7 \mathrm{C})$. Note that in a cubic faujasite, all the $\mathrm{K}^{+}\left(\mathrm{SI}^{\prime}\right)-\mathrm{K}^{+}(\mathrm{SI}$ ') distances are equal inside the sodalite cages.

Insert Figure 7

\subsection{Charge analysis and cation-cation interactions}

Although the volume of a $\mathrm{K}^{+}$cation is 2.6 times larger than that of a $\mathrm{Na}^{+}$cation, $\mathrm{K}^{+}$cations prefer to crowd into sites I, I' and II rather than to occupy sites III [30, and references therein]. In order to understand the monitoring effects that may govern the preference of sodium and potassium cations to sit in a specific location inside the hexagonal prism, we have analyzed, through the Natural Bond Orbital (NBO) analysis, the variation of cation charges as a function of the cation-cation distances inside the hexagonal prism. In Figure 8 are reported, from single point energy calculations, both total energy (energy profile along the [111] axis) and NBO cation charge variations for the K-LSX and Na-LSX systems. Starting from configuration 3, the energy scan was conducted by fixing in SI' sites the location of one of the cations (charge denoted Q1) and varying the other one (Q2) along the [111] axis. As illustrated in figure $8 \mathrm{~A}$, the energy profile along the K-LSX 3-fold axis shows two minima corresponding to the $\mathrm{K}^{+}\left(\mathrm{SI}^{\prime}\right)-\mathrm{K}^{+}\left(\mathrm{SI}^{\prime}\right)$ and $\mathrm{K}^{+}(\mathrm{SIa})-\mathrm{K}^{+}$(SI') equilibrium distances. Let us note that the equilibrium geometries (EG) can be regained by re-optimizing the geometries with the minimum energy on the energy profile by mean of full relaxation. Thus, as described above, the local minima for configuration with $\mathrm{K}^{+}$sitting in SIa-SI' positions can be found with an energy value similar to that in SI'-SI' positions. The analysis of potassium charges (Figure $8 \mathrm{~B}$ ) shows that for $\mathrm{dK}^{+}-\mathrm{K}^{+}$distances less than $3.6 \AA$, one of the two potassium 
cations (the potassium which position is varied along the 3-fold axis) highly looses in its charge. Beyond that distance the two cations have equivalent charges of about $+0.93|\mathrm{e}|$. Thus, the original SI'-SIa position which bond length was predicted by theoretical calculations and confirmed by experimental measurements seems to correspond to the shortest distance allowed in a stable potassium distribution. That distance may be correlated to the electrostatic range in such distribution. Finally, in contrast with K-LSX system, the Na-LSX energy scan shows a single minimum which confirms the unique equilibrium configuration found for this system where sodium cations occupy the two available SI' sites outside the hexagonal prism. The NBO sodium charge analysis (Figure 8D) indicates Q1 $=\mathrm{Q} 2=+0.91|\mathrm{e}|$ for the structure

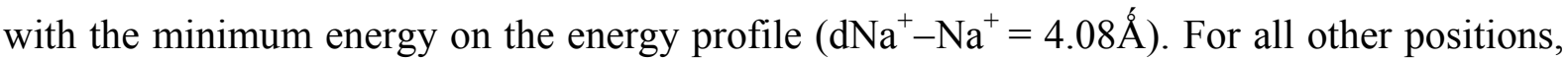
the charge $(\mathrm{Q} 2)$ of the sodium cation, scanning the 111 axis, highly decrease which affects the stability of the Na-LSX system.

\section{Insert Figure 8}

To further understand the equivalent charges of potassium cations and to analyze the effect of long range distribution, we have performed optimization calculations of the whole sodalite cage (180 atoms). In the starting model, we have considered configuration 4 ( $\mathrm{K}^{+}$in sites SI' and SIa) to locate the potassium cations in the four hexagonal prisms connected to the sodalite cage. The geometry optimization shows an equilibrium geometry illustrated by Figure 9 where both sites SI' and SIa within all the hexagonal prisms are simultaneously occupied by potassium cations. Similarly to the calculation made with the extended hexagonal prism model, the average $\mathrm{dK}^{+}\left(\mathrm{SI}^{\prime}\right)-\mathrm{K}^{+}$(SIa) distance is found to be $3.59 \AA$, and only one short distance of $3.57 \AA$ exists between two SI' sites inside the sodalite cage. These geometric results are in full agreement with the experimental results illustrated by Figure 7A. The 
analysis of the corresponding potassium NBO charges reveals equivalent charges of all $\mathrm{K}^{+}$ cations and especially cations in (SIa-SI'-SI'-SIa) connecting two hexagonal prisms. The slightly different potassium cation charges predicted in the two SI' sites of the other hexagonal prisms may be induced by the effect of bordering, an artifact of clustering method. Otherwise, if we consider the principle of periodicity it appears that all potassium cations inside the hexagonal prisms may have an equivalent charge. This can be achieved in presence of specific $\mathrm{dK}^{+}-\mathrm{K}^{+}$distances for $\mathrm{K}^{+}$cations in the sites with the highest charge density, site SI' inside the sodalite cage and site SIa in the hexagonal prism. The most favorable coordination conditions are realized for similar and short distances of about $3.6 \AA$ between SIa and SI' sites, such circumstances allows a strong electrostatic stability and is responsible of this K-LSX peculiar case.

\section{Insert Figure 9}

\section{Conclusion}

In this work, we have investigated from a theoretical and experimental point of views the location of the counter potassium cations in fully exchanged and fully dehydrated LSX zeolite. Our theoretical results performed with the Density Functional Theory (DFT) corroborate the structural study performed on a polycrystalline sample. The structure analysis performed by the Rietveld technique has been associated to a new experimental knowledge achieved from gravimetric (TG) measurements which confirms a suspected adsorption of some argon molecules during the sample preparation which have been located inside the supercages near the SV sites. Also, the specific simultaneous occupancy of site SIa (SI site shifted from the centre of the hexagonal prism) and SI' by $\mathrm{K}^{+}$cations has been explained by comparing calculations performed on Na-LSX, taken as a reference system. Thus, the $\mathrm{K}^{+}-\mathrm{K}^{+}$ 
distance involving SI' and SIa sites seems to correspond to the shorts potassium bond length configuration from which the charge of all cations become equivalent.

ACKNOWLEDGMENT. This work was granted access to the HPC resources of [CCRT/CINES/IDRIS] under the allocation 2010 [x2010086395] made by GENCI (Grand Equipement National de Calcul Intensif]. We thank Michel Soulard of IS2M for fruitful discussion.

APPENDIX A. SUPPLEMENTARY DATA. Tables of inter atomic distances and angles, Tables S1, S2 and S3, crystallographic information information files (CIF). This material associated with this article can be found, in the online version, at doi:10.10xx/j.micromeso.20xx.xx.xxx. 
Table 1: Crystal and Rietveld refinement data for the dehydrated K-LSX zeolite.

\begin{tabular}{|c|c|}
\hline Chemical formula (refined) & $\mathrm{Si}_{2} \mathrm{Al}_{2} \mathrm{O}_{8} \mathrm{~K}_{1.952} \mathrm{Ar}_{0.065}$ \\
\hline Space group & Fddd (no. 70$)$ \\
\hline$\lambda(\AA), \mathrm{CuK} \alpha_{1}$ & 1.5406 \\
\hline Data collection temperature $\mathrm{T}(\mathrm{K})$ & 293 \\
\hline$a(\AA)$ & $25.3198(4)$ \\
\hline$b(\AA)$ & $25.1894(7)$ \\
\hline$c(\AA)$ & $25.1618(7)$ \\
\hline$V\left(\AA^{3}\right)$ & $16047.96(68)$ \\
\hline$Z$ & 48 \\
\hline Number of data points $\left(\operatorname{step}\left({ }^{\circ} 2 \theta\right)\right)$ & $7598(0.01)$ \\
\hline Number of contributing reflections & 1428 \\
\hline Number of structural parameters & 76 \\
\hline Number of profile parameters & 18 \\
\hline Total number of restraints (bonds, angles) & $60(24,36)$ \\
\hline Total number of constraints & 21 \\
\hline${ }^{\mathrm{a}} \mathrm{R}_{\mathrm{p}}=\Sigma\left\{\left[\left|\mathrm{y}_{\mathrm{o}}-\mathrm{y}_{\mathrm{c}}\right| \times\left|\mathrm{y}_{\mathrm{o}}-\mathrm{y}_{\mathrm{b}}\right| / \mathrm{y}_{\mathrm{o}}\right] / \Sigma\left|\mathrm{y}_{\mathrm{o}}-\mathrm{y}_{\mathrm{b}}\right|\right\}$ & 0.0382 \\
\hline${ }^{\mathrm{a}} \mathrm{wR}_{\mathrm{p}}=\left\{\Sigma\left[\mathrm{w} \times\left(\mathrm{y}_{\mathrm{o}}-\mathrm{y}_{\mathrm{c}}\right) \times\left(\mathrm{y}_{\mathrm{o}}-\mathrm{y}_{\mathrm{b}}\right) / \mathrm{y}_{\mathrm{o}}\right]^{2} / \Sigma\left[\mathrm{w} \times\left(\mathrm{y}_{\mathrm{o}}-\mathrm{y}_{\mathrm{b}}\right)^{2}\right]\right\}^{1 / 2}$ & 0.0543 \\
\hline${ }^{\mathrm{b}} \mathrm{R}_{\exp }$ & 0.0338 \\
\hline${ }^{\mathrm{b}} \mathrm{R}_{\mathrm{F}}$ & 0.0350 \\
\hline${ }^{\mathrm{b}} \mathrm{R}_{\mathrm{F}}{ }^{2}$ & 0.0547 \\
\hline $\mathrm{b}^{2}$ & 2.618 \\
\hline Largest diff. peak and hole (e. $\left.\AA^{-3}\right)$ & $0.415,-0.404$ \\
\hline
\end{tabular}

${ }^{\mathrm{a}} \mathrm{y}_{\mathrm{o}}, \mathrm{y}_{\mathrm{c}}, \mathrm{y}_{\mathrm{b}}$ are y observed, y calculated and y background, respectively.

${ }^{b}$ The definition of these residual values are given in references [16a]. 
Table 2: Experimental atomic coordinates (numbers in parentheses are the esd's in the units of the least significant digit given.), Wyckoff positions, site occupancy factors (s.o.f) and equivalent isotropic displacement parameters (U) for the dehydrated K-LSX zeolite.

\begin{tabular}{|c|c|c|c|c|c|c|}
\hline Atoms & Wyck. $^{a}$ & s.o.f. & $\mathrm{x} / \mathrm{a}$ & $y / b$ & $\mathrm{z} / \mathrm{c}$ & $\mathrm{U}\left[\AA^{2}\right]$ \\
\hline Sil & $32 \mathrm{~h}$ & 1 & $-0.0490(3)$ & $0.1249(4)$ & $0.0341(4)$ & $0.0080(5)$ \\
\hline $\mathrm{Si} 2$ & $32 \mathrm{~h}$ & 1 & $0.0357(4)$ & $-0.0558(3)$ & $0.1302(4)$ & $0.0080(5)$ \\
\hline $\mathrm{Si} 3$ & $32 \mathrm{~h}$ & 1 & $0.1276(3)$ & $0.0342(3)$ & $-0.0611(4)$ & $0.0080(5)$ \\
\hline Al1 & $32 \mathrm{~h}$ & 1 & $-0.0522(3)$ & $0.0359(4)$ & $0.1253(4)$ & $0.0080(5)$ \\
\hline $\mathrm{A} 12$ & $32 \mathrm{~h}$ & 1 & $0.1201(3)$ & $-0.0532(3)$ & $0.0360(4)$ & $0.0080(5)$ \\
\hline $\mathrm{Al} 3$ & $32 \mathrm{~h}$ & 1 & $0.0361(4)$ & $0.1270(4)$ & $-0.0630(4)$ & $0.0080(5)$ \\
\hline $\mathrm{O} 1$ & $32 \mathrm{~h}$ & 1 & $-0.1116(5)$ & $0.0065(5)$ & $0.1073(5)$ & $0.0056(7)$ \\
\hline $\mathrm{O} 2$ & $32 \mathrm{~h}$ & 1 & $0.0991(5)$ & $-0.1085(5)$ & $0.0022(6)$ & $0.0056(7)$ \\
\hline $\mathrm{O} 3$ & $32 \mathrm{~h}$ & 1 & $-0.0067(6)$ & $0.1097(5)$ & $-0.1128(5)$ & $0.0056(7)$ \\
\hline $\mathrm{O} 4$ & $32 \mathrm{~h}$ & 1 & $-0.0065(5)$ & $-0.0110(4)$ & $0.1453(5)$ & $0.0056(7)$ \\
\hline $\mathrm{O} 5$ & $32 \mathrm{~h}$ & 1 & $0.1333(5)$ & $0.0004(5)$ & $-0.0062(5)$ & $0.0056(7)$ \\
\hline O6 & $32 \mathrm{~h}$ & 1 & $0.0016(5)$ & $0.1359(5)$ & $-0.0040(5)$ & $0.0056(7)$ \\
\hline $\mathrm{O} 7$ & $32 \mathrm{~h}$ & 1 & $-0.0339(5)$ & $0.0741(5)$ & $0.0711(5)$ & $0.0056(7)$ \\
\hline $\mathrm{O} 8$ & $32 \mathrm{~h}$ & 1 & $0.0700(6)$ & $-0.0363(5)$ & $0.0801(6)$ & $0.0056(7)$ \\
\hline O9 & $32 \mathrm{~h}$ & 1 & $0.0806(5)$ & $0.0764(5)$ & $-0.0526(5)$ & $0.0056(7)$ \\
\hline $\mathrm{O} 10$ & $32 \mathrm{~h}$ & 1 & $-0.0667(5)$ & $0.0762(5)$ & $0.1789(5)$ & $0.0056(7)$ \\
\hline O11 & $32 \mathrm{~h}$ & 1 & $0.1765(5)$ & $-0.0687(5)$ & $0.0703(6)$ & $0.0056(7)$ \\
\hline $\mathrm{O} 12$ & $32 \mathrm{~h}$ & 1 & $0.0670(4)$ & $0.1872(5)$ & $-0.0751(5)$ & $0.0056(7)$ \\
\hline K(SIa) & $32 \mathrm{~h}$ & $0.495(3)$ & $-0.0119(5)$ & $-0.0111(8)$ & $-0.0079(8)$ & $0.0185(9)$ \\
\hline K(SII) & $32 \mathrm{~h}$ & 1 & $0.2423(2)$ & $0.0069(3)$ & $0.0056(3)$ & $0.0185(9)$ \\
\hline $\mathrm{K}(\mathrm{SI})$ & $32 \mathrm{~h}$ & $0.491(4)$ & $0.0765(5)$ & $0.0751(5)$ & $0.0573(4)$ & $0.0185(9)$ \\
\hline K(SIII1) & $16 \mathrm{e}$ & $0.882(9)$ & $0.3990(3)$ & 0.125 & 0.125 & $0.0185(9)$ \\
\hline K(SIII2) & $16 \mathrm{f}$ & 1 & 0.625 & $0.3468(3)$ & 0.125 & $0.0185(9)$ \\
\hline $\operatorname{Ar}(\mathrm{SV})$ & $32 \mathrm{~h}$ & $0.098(5)$ & $0.716(3)$ & $0.186(3)$ & $0.036(4)$ & $0.10(5)$ \\
\hline
\end{tabular}

\footnotetext{
${ }^{\mathrm{a}}$ Multiplicity and Wyckoff letter
} 
Table 3: Cationic sites occupancies in the four considered initial configurations; DFT optimized energies and energy differences relative to the energetically most stable configuration for each alkali-LSX system (in brackets and italic).

\begin{tabular}{llllll}
\hline Configuration & & 1 & 2 & 3 & 4 \\
\hline $\begin{array}{l}\text { Cationic site occupancy as } \\
\text { defined initially in the }\end{array}$ & SI & 0 & 1 & 0 & 1 \\
$\begin{array}{l}\text { extended hexagonal prism } \\
\text { cluster }\end{array}$ & SII & 0 & 0 & 2 & 1 \\
& SIII & 6 & 6 & 6 & 6 \\
$\begin{array}{l}\text { Total energy after } \\
\text { optimization (Hartree) and }\end{array}$ & K-LSX & -18118.72 & -18118.78 & -18118.80 & -18118.80 \\
energy difference (kJ.mol ${ }^{-1}$ ) & Na-LSX & $(+210)$ & $(+50)$ & $(0)$ & $(0)$ \\
& & $(+236)$ & $(+105)$ & $(0)$ & No PES $^{\mathrm{a}}$ \\
& & & & & \\
\hline
\end{tabular}

${ }^{a}$ Potential Energy Surface 


\section{Figure captions}

Figure 1: (A) Schematic representation of cages in the cubic faujasite (FAU) structure and location of the well-referenced cationic sites; (B) same representation for dehydrated K-LSX showing the potassium and adsorbed Ar atoms sites located from the present structural study performed by the Rietveld method. The represented [1,1,1] axis corresponds to the one found in a cubic faujasite (no 3-fold axis in the Fddd space group).

Figure 2: Rietveld plots of dehydrated K-LSX $\left(\lambda=1.5406 \AA \mathrm{Cuk}_{\alpha 1}\right)$, experimental $(\times)$, calculated (solid red line) and background (solid green line). Vertical magenta ticks are the positions of the theoretical reflections for space group Fddd. The lowest trace (solid blue line) is the difference plot. The low angles part $\left(26-80^{\circ}\right)$ is magnified by a factor of 12 .

Figure 3: Argon adsorption isotherm for dehydrated K-LSX performed at 295K (filled rhombs: adsorbed volumes, empty squares: Ar atoms per unit cell).

Figure 4: Perspective showing the five $\mathrm{K}^{+}$and the Ar refined sites positions in dehydrated K-LSX (see Table S1 for details on $\mathrm{K}-\mathrm{O}, \mathrm{K}-\mathrm{K}$ and $\mathrm{Ar}-\mathrm{O}, \mathrm{K}$ bond distances values).

Figure 5: (A) K-free cluster model of the extended hexagonal prism used for DFT calculations (hydrogen terminations are represented by small white balls); (B), (C) and (D) upper and side views of the optimized K-LSX hexagonal prisms (modelled by starting from configurations 2,3 and 4, respectively) and resulted bond distances in $\AA$. The white, red, purple and yellow balls represent K, O, Al and Si atoms, respectively. For clarity, the framework atoms outside the prism are not represented in the upper and side views.

Figure 6: Side (A) and upper (B) views of the hexagonal prism with the corresponding 
experimental distance values in $\AA$ providing details on the coordination sphere of SIa and SI' potassium sites, the corresponding distances are listed in Table S1. The vertical straight line corresponds to the $[1,1,1]$ axis found in a cubic faujasite and the black dot is the central position (reduced atomic coordinates $(0,0,0)$ ) of the hexagonal prism.

Figure 7: Three possible $\mathrm{K}^{+}$arrangements inside the sodalite cages and hexagonal prisms of dehydrated K-LSX as established by the present structural study. The shortest $\mathrm{K}^{+}-\mathrm{K}^{+}$distances are alighted (dashed bonds). In all cases, the $\mathrm{K}^{+}$(SIa) $-\mathrm{K}^{+}$(SI') bond distance is 3.52(1) $\AA$.

Figure 8: Total energy profiles and NBO cation charge variations computed from single point energy calculations along the [111] axis of the K-LSX (A, B) and Na-LSX (C, D) systems.

Figure 9: Cation-cation distances (in $\AA$ ) and potassium NBO charges, Q1 and Q2 (in bold and italic) calculated in the sodalite cage (180 atoms) representing the K-LSX system. 
Figure 1

A

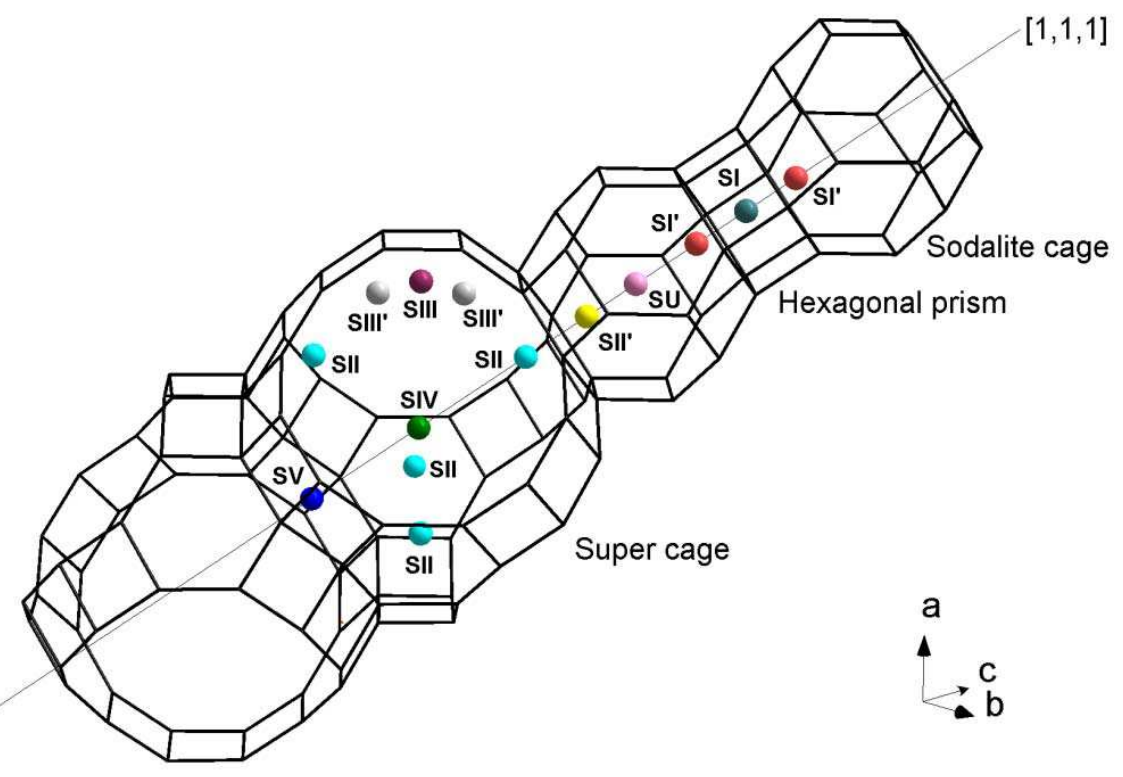

B

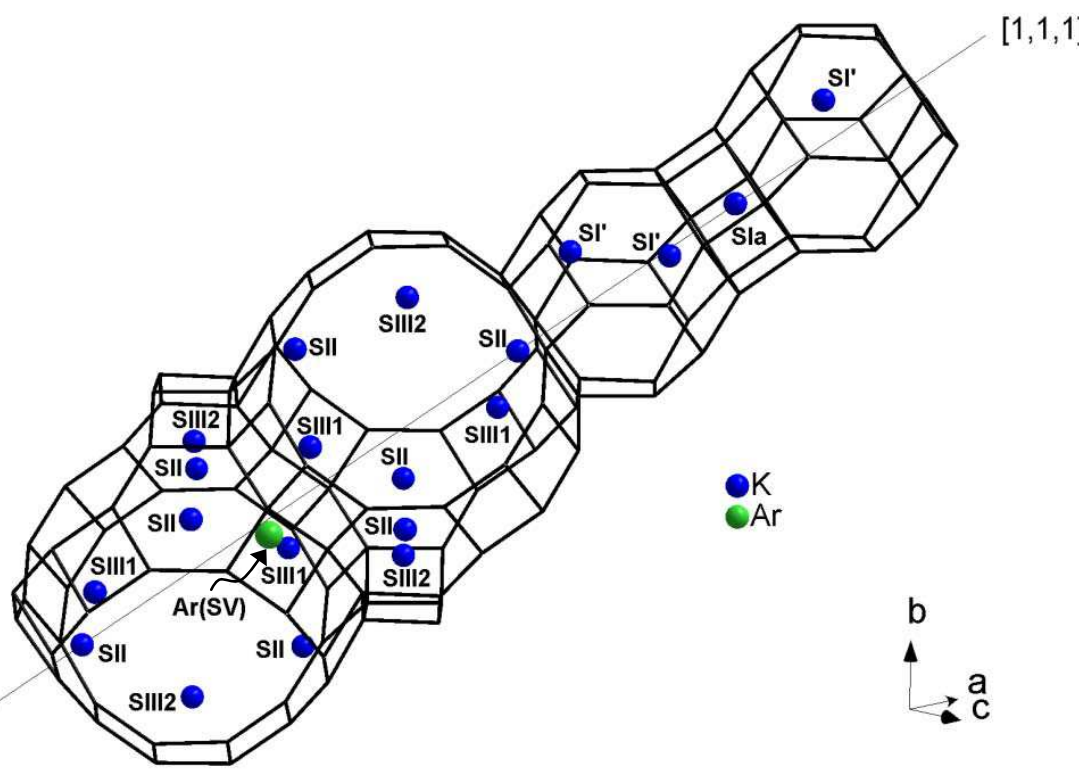


Figure 2

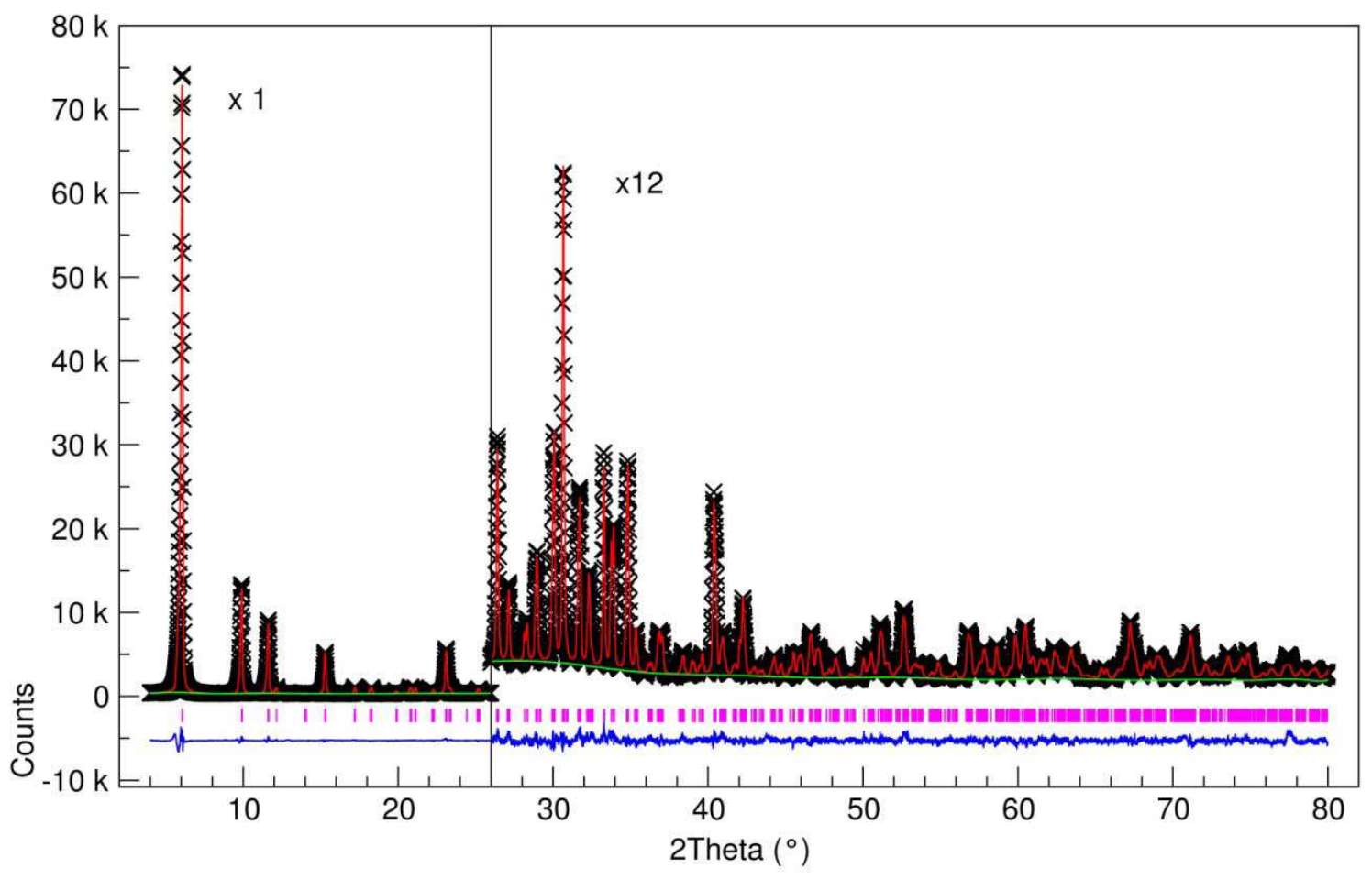


Figure 3

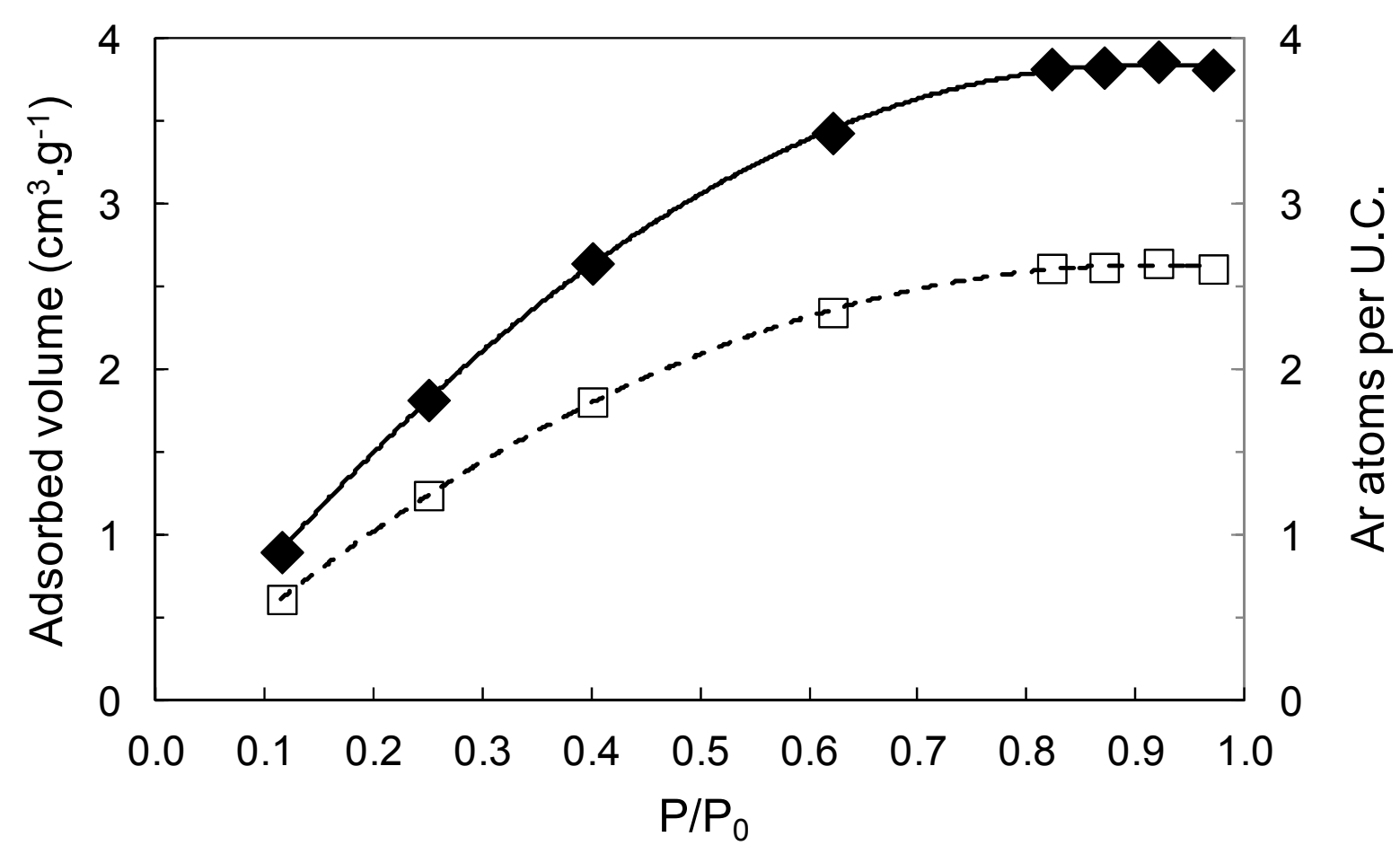


Figure 4

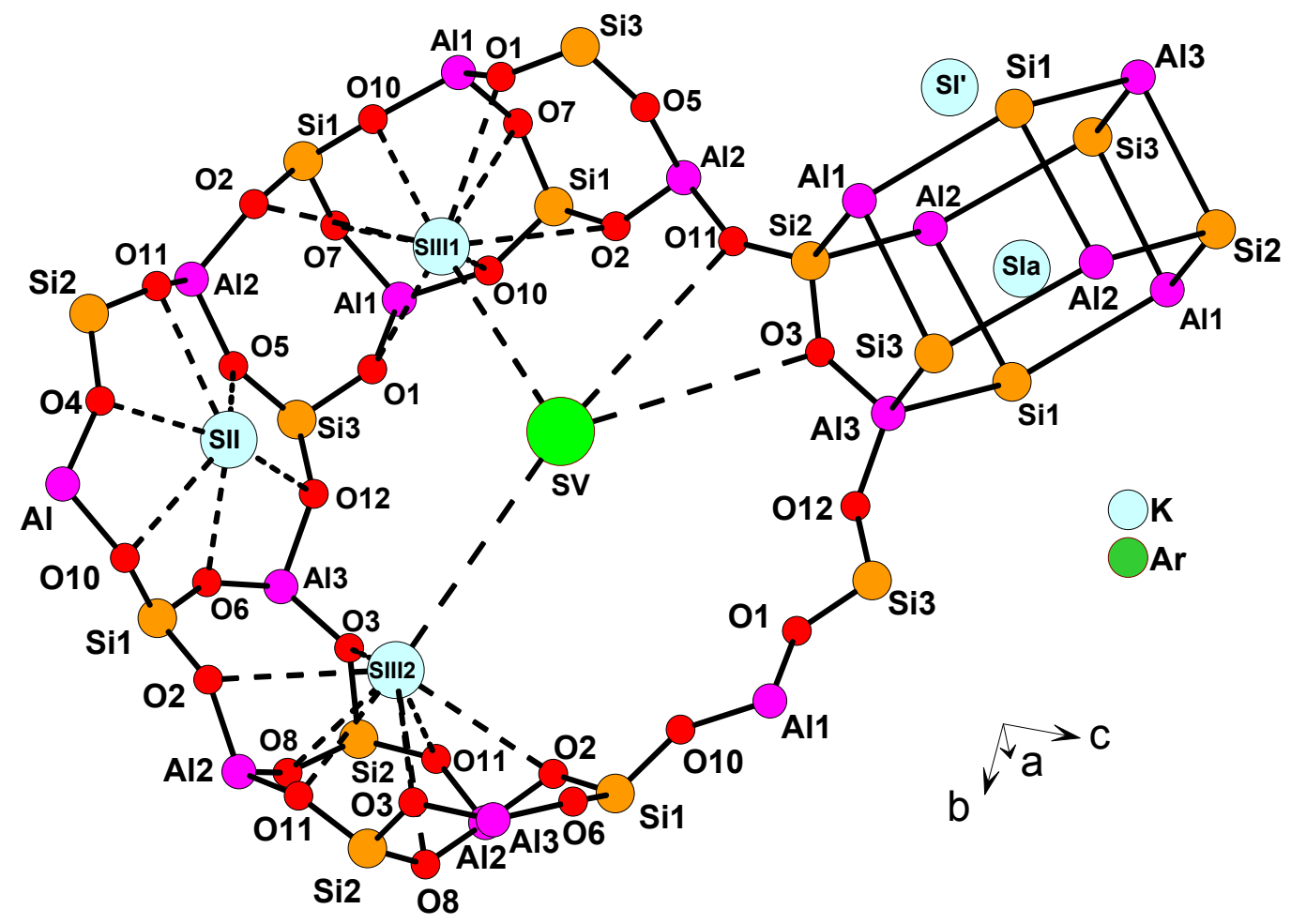


Figure 5

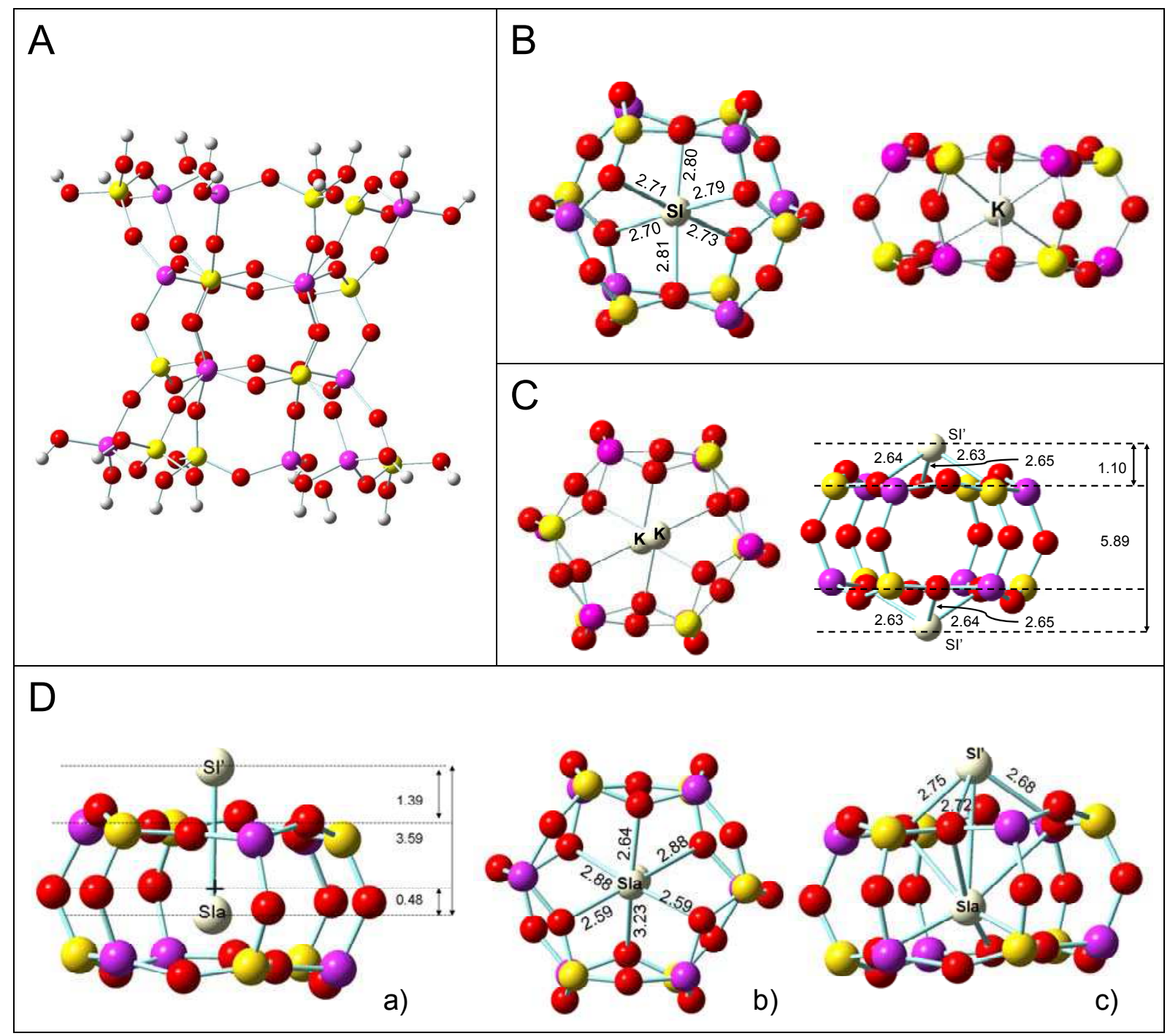


Figure 6
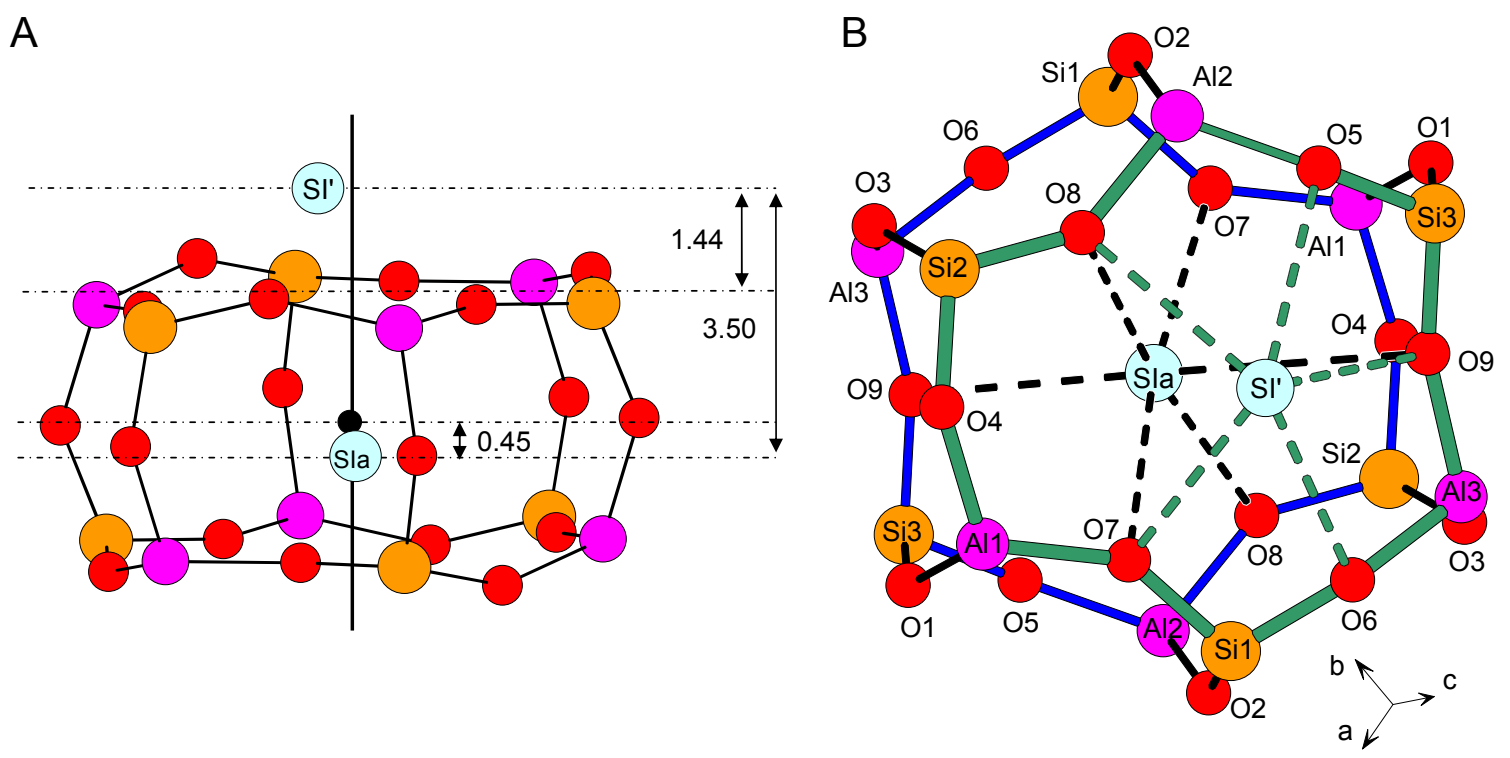
Figure 7

A

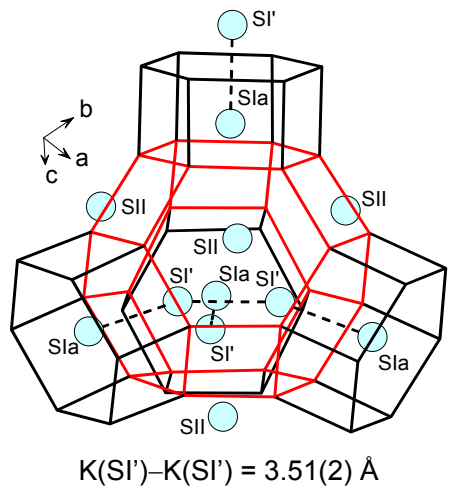

B

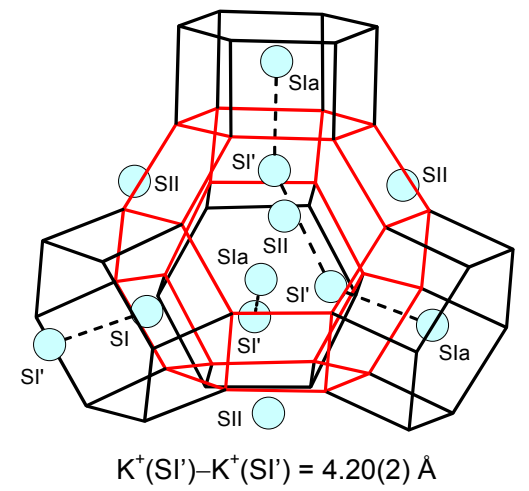

C

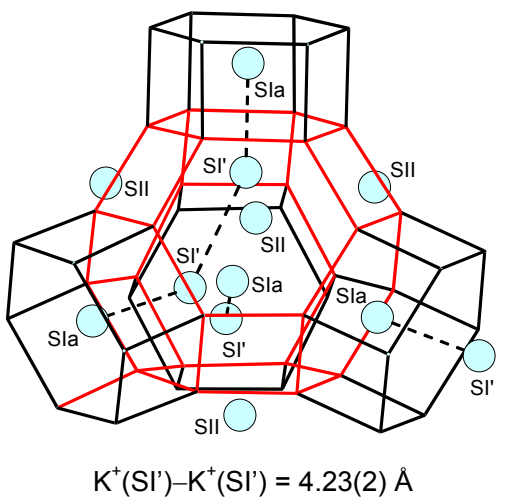


Figure 8

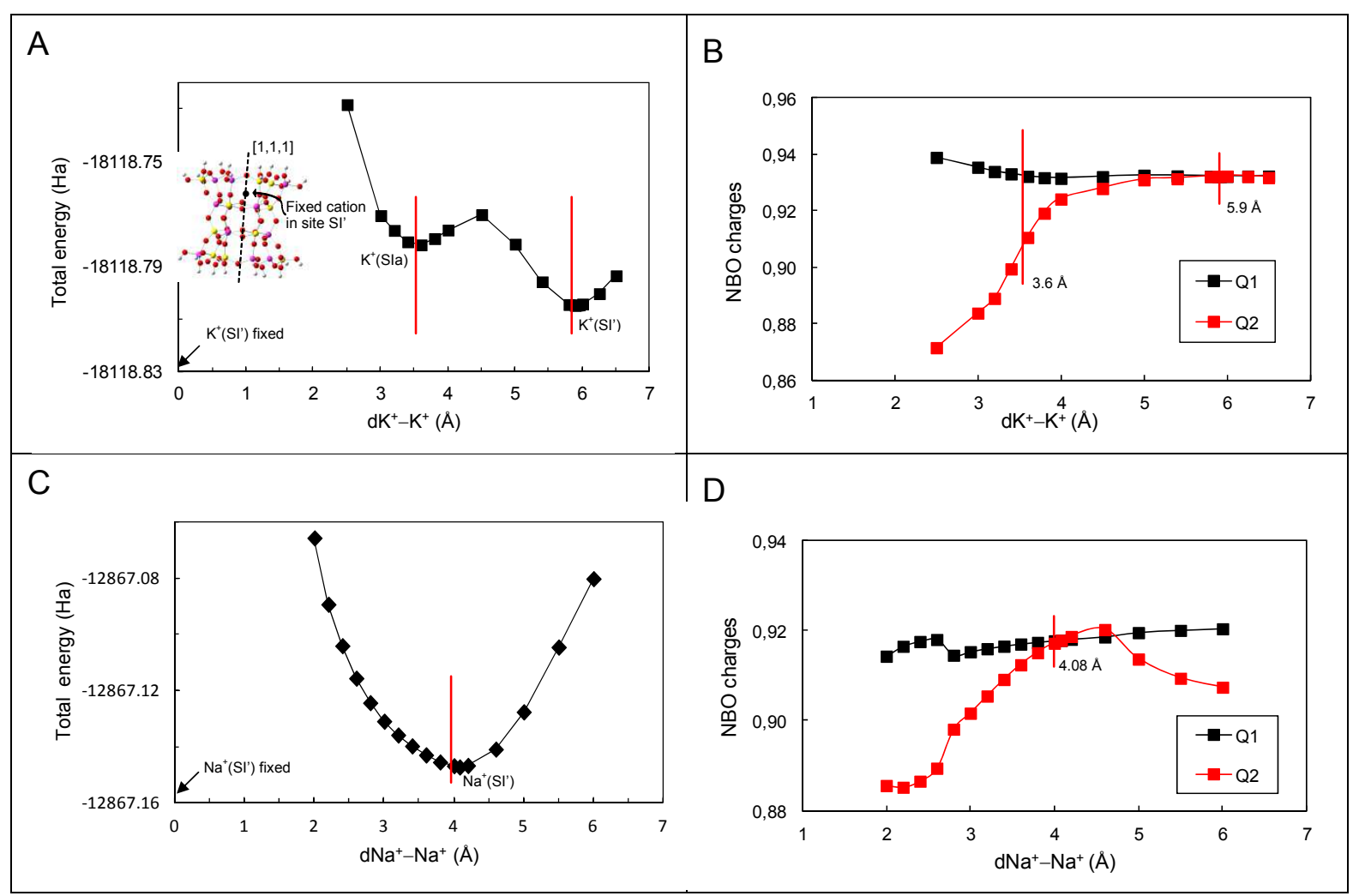


Figure 9

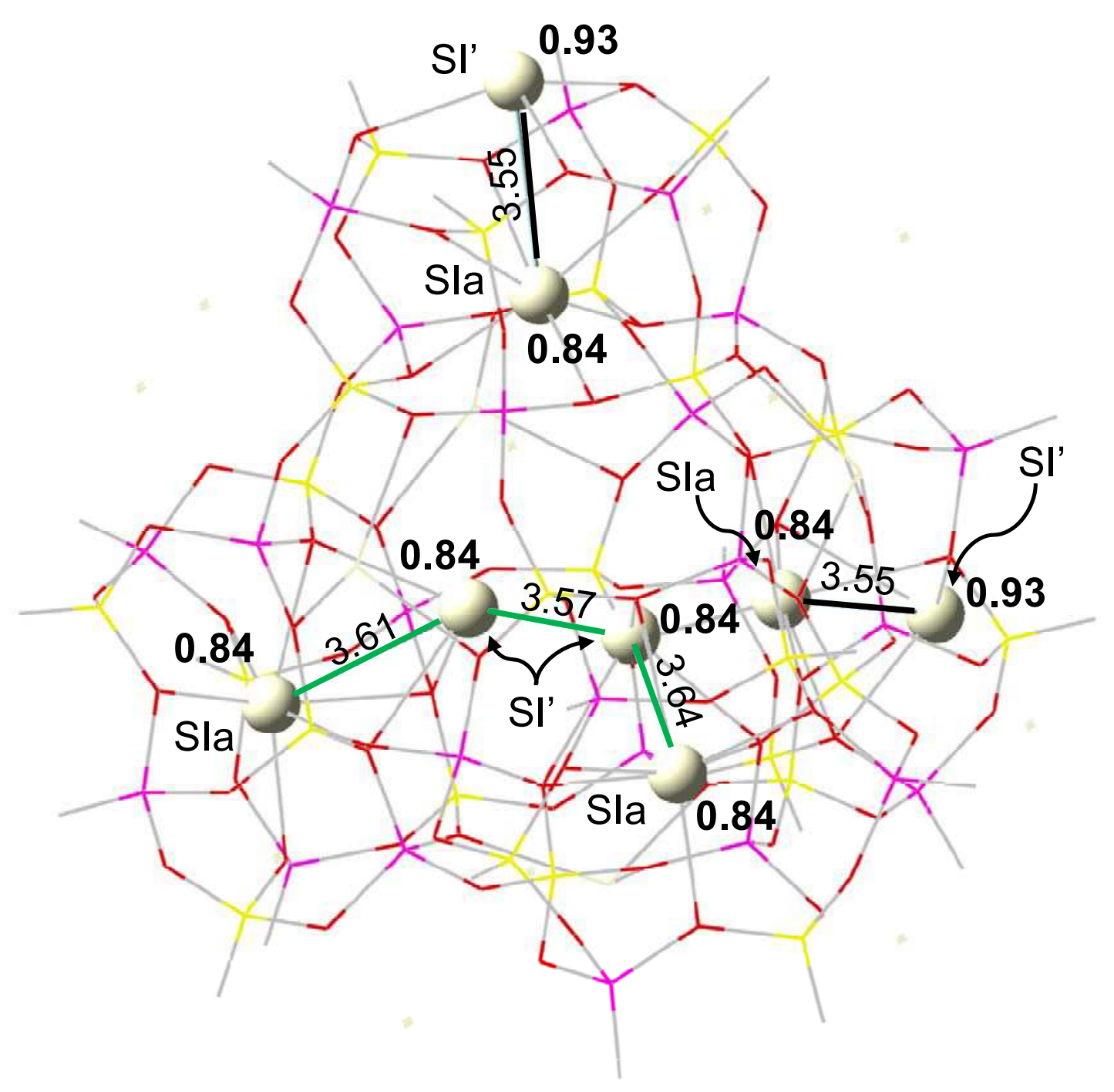




\section{References}

1 J.V. Smith, Faujasite-type structures: aluminosilicate framework: positions of cations and molecules: nomenclature, in: E.M. Flanigen, L.B. Sand (Eds.), Molecular Sieve ZeolitesI, American Chemical Society, Washington, DC, 1971, pp. 171-200.

2 W.J. Mortier, Compilation of Extra-framework Sites in Zeolites, Butterworths, Guildford, 1982.

3 W. J. Mortier, H. J. Bosmans, J. Phys. Chem. 75 (1971) 3327.

4 C. Beauvais, A. Boutin, A. H. Fuchs, C. R. Chim. 8 (2005) 485.

5 T. Frising, P. Leflaive, Micropor. Mesopor. Mater. 114 (2008) 27.

6 H. Guesmi, D. Costa, D. Berthomieu, P. Massiani, J. Phys. Chem. C 115 (2011) 5607.

7 H. Guesmi, P. Massiani, Catal. Today 177 (2011) 25.

8 B. F. Mentzen, C. R. Chimie 8 (2005) 353.

9 W. J. Mortier, H. J. Bosmans, J. B. Uytterhoeven, J. Phys. Chem. 76 (1972) 650.

10 J.-L. Paillaud, P. Caullet, L. Delmotte, J.-C. Mougenel, S. Kayiran, B. Lledos, Stud. Surf. Sci. Catal. 135 (2001) 163.

11 (a) L. Zhu, K. Seff, J. Phys. Chem. B 104 (2000) 8946, (b) L. Zhu, K. Seff, J. Phys. Chem. B 105 (2001) 12221.

12 W. Loewenstein, Am. Mineral., 39 (1954) 92.

13 T. Gibbs, D. W. Lewis, Chem. Commun. (2002) 2660.

14 N. Riisch, V. A. Nasluzov, K. M. Neyman, G. Pacchionff, G. N. Vayssilov, J. Leszczynski (Eds.), Computational Materials Science Theoretical and Computational Chemistry, vol. 15-9, Elsevier B.V., Amsterdam, 2004.

15 H. Guesmi, D. Berthomieu, L. Kiwi-Minsker, Stud. Surf. Sci. Catal., 174 (2008) 1123. 
16 (a) A. C. Larson, R. B. Von Dreele, General Structure Analysis System, Los Alamos National Laboratory Report LAUR 86-748, 2000. (b) B. H. Toby, J. Appl. Crystallogr. 34 (1994) 210.

17 G. Vitale, C. F. Mellot, L. M. Bull, A. K. Cheetham, J. Phys. Chem. B 101 (1997) 4559.

18 M. J. Frisch, G. W. Trucks, H. B. Schlegel, G. E. Scuseria, M. A. Robb, J. R. Cheeseman, J. A. Montgomery, Jr., T. Vreven, K. N. Kudin, J. C. Burant, J. M. Millam, S. S. Iyengar, J. Tomasi, V. Barone, B. Mennucci, M. Cossi, G. Scalmani, N. Rega, G. A. Petersson, H. Nakatsuji, M. Hada, M. Ehara, K. Toyota, R. Fukuda, J. Hasegawa, M. Ishida, T. Nakajima, Y. Honda, O. Kitao, H. Nakai, M. Klene, X. Li, J. E. Knox, H. P. Hratchian, J. B. Cross, V. Bakken, C. Adamo, J. Jaramillo, R. Gomperts, R. E. Stratmann, O. Yazyev, A. J. Austin, R. Cammi, C. Pomelli, J. W. Ochterski, P. Y. Ayala, K. Morokuma, G. A. Voth, P. Salvador, J. J. Dannenberg, V. G. Zakrzewski, S. Dapprich, A. D. Daniels, M. C. Strain, O. Farkas, D. K. Malick, A. D. Rabuck, K. Raghavachari, J. B. Foresman, J. V. Ortiz, Q. Cui, A. G. Baboul, S. Clifford, J. Cioslowski, B. B. Stefanov, G. Liu, A. Liashenko, P. Piskorz, I. Komaromi, R. L. Martin, D. J. Fox, T. Keith, M. A. Al-Laham, C. Y. Peng, A. Nanayakkara, M. Challacombe, P. M. W. Gill, B. Johnson, W. Chen, M. W. Wong, C. Gonzalez, and J. A. Pople, Gaussian 03, Revision C.02, Gaussian, Inc., Wallingford CT, 2004.

19 A. D. Becke, Phys. Rev. A 38 (1988) 3098.

20 C. Lee, W. Yang, R. G. Parr, Phys. Rev. B 37 (1988) 785.

21 S. F. Boys, F. Bernradi, J. Mol. Phys. 19 (1970) 553.

22 C. E. A. Kirschhock, B. Hunger, J. Martens, P. A. Jacobs, J. Phys. Chem. B 104 (2000) 439.

23 K. Brandenburg, H. Putz, Diamond software - Crystal and Molecular Structure Visualization Crystal Impact, GbR, Rathausgasse 30, D-53111 Bonn. 
24 T. Frising, P. Leflaive, Micropor. Mesopor. Mater. 114 (2008) 27.

25 T. Frising, P. Leflaive, C. Pichon, A. A. Quoineaud, Stud. Surf. Sci. Catal. 174B (2008) 833.

26 C. Abrioux, B. Coasne, G. Maurin, F. Henn, A. Boutin, A. Di Lella, C. Nieto-Draghi, A. H. Fuchs, Adsorption 14 (2008), 743. and references therein.

27 A. Di Lella, Ph.D. thesis, Université Paris Sud, 2007, and references therein.

28 D. W. Breck, Zeolite Molecular Sieves; John Wiley \& Son: New York, 1973; p 579.

29 Y. Lee, S. W. Carr, J. B. Parise, Chem. Mater. 10 (1998) 2561.

30 W. T. Lim, S. Y. Choi, J. H. Choi, Y. H. Kim, N. H. Heo, K. Seff, Micropor. Mesopor. Mater. 92 (2006) 234. 